\title{
Erratum to: The Poetics \\ of Non-Indigenous Reflexive \\ Self-awareness: Strategies of Embodiment \\ and Delegation in Focus Group \\ Discussions in Australia
}

Angélique Stastny, Sasha Henriss-Anderssen and Tom Clark

Erratum to:

Chapter 10 in: S. Maddison et al. (eds.), The Limits of Settler Colonial Reconciliation, DOI 10.1007/978-981-10-2654-6_10

The original version of the book was inadvertently published with chapter author names as keywords in Chapter 10. The erratum chapter has been updated with the correct keywords.

The updated original online version for this chapter can be found at 10.1007/978-981-10-2654-6_10

\footnotetext{
A. Stastny $(\square)$

University of Melbourne, Parkville, Australia

e-mail: a.stastny@student.unimelb.edu.au

S. Henriss-Anderssen · T. Clark

Victoria University, Melbourne, Australia

e-mail: Sasha.Henriss-Andersse@vu.edu.au

T. Clark

e-mail: Tom.Clark@vu.edu.au 